\title{
Free Latismus Dorsi Muscle Flap with a Flow-Through Technique for Lower Limb Salvage
}

\author{
Wael M. Ayad, Abdelnaser Hamdi Mohammed, Hany M. Ismail, Mohamed Osama Ouf, Amr M. Elbatawy \\ Department of Plastic and Burn Surgery, Al Azhar University, Cairo, Egypt
}

Purpose: The lower limb injuries still one of the devastating problems in surgical practice. Complex defects may affect one major vessel that supplies the distal portion of the leg and foot. The use of the flow-through technique is a very useful tool for sure vascularization of the flap and revascularization of the distal limb at the same time. The aim of this study was to evaluate the advantages of the use of the flow-through technique for lower limb reconstruction.

Methods: This retrospective study was including 15 patients complaining of post-traumatic leg and/or foot defects. Free latissimus muscle transfer with the flow-through technique was done for lower limb reconstruction. The subscapular artery was anastomosed to the proximal segment of the limb vessel and the circumflex scapular artery anastomosed to the distal segment of the limb vessel. Follow-up was for six months.

Results: Patients were followed for 6 months. All flaps were survived and there were no anastomotic complications.

Conclusion: The use of the flow-through technique is a very useful tool for vascularization of the flap and revascularization of the distal limb at the same time.

Key Words: Free tissue transfer flaps, Lower limb, Reconstructive surgical procedure, Microsurgical free flap

\section{INTRODUCTION}

Lower limb injuries lead to significant morbidity and may affect the lifestyle of the patient. These injuries may be severe and extensive that necessitates free tissue transfer. Free tissue transfer is commonly indicated in limbsparing surgery for leg reconstruction but is known to have a higher failure rate than transfers to the other body regions ${ }^{1}$.

The ideal method for arterial anastomosis for leg free tissue transfer, end-to-end versus end-to-side anastomosis, has been evaluated. There was no significant differ- ence in success rates ${ }^{2-4}$. Flow-through anastomosis was introduced by Soutar et al. ${ }^{5}$ in 1983 as a third method and its clinical application has been expanding in free tissue transfer for leg reconstruction. Several hemodynamic advantages of flow-through anastomosis resulting in revascularization of the distal limb and flap in one stage $e^{6-8}$. The latissimus dorsi (LD) muscle flap is a workhorse flap and has many advantages for soft-tissue reconstruction in lower limb reconstruction?

Received July 25, 2018, Revised [1] December 20, 2018, [2] January 6, 2019, Accepted March 12, 2019

Corresponding author: Amr M. Elbatawy

Department of Plastic and Burn Surgery, Al Azhar University, 148 Elsad st., Cairo 11511, Egypt

TEL: +20-1113033384, FAX: +20-25326791, E-mail: Amrelbatawy@azhar.edu.eg, ORCID: https://orcid.org/0000-0003-2562-7291

Copyright (c) 2019 by Korean Society for Surgery of the Hand, Korean Society for Microsurgery, and Korean Society for Surgery of the Peripheral Nerve. All Rights reserved.

This is an Open Access article distributed under the terms of the Creative Commons Attribution Non-Commercial License (http://creativecommons.org/licenses/by-nc/4.0/) which permits unrestricted non-commercial use, distribution, and reproduction in any medium, provided the original work is properly cited. 


\section{MATERIALS AND METHODS}

\section{Patients and methods}

This retrospective study was done on 15 patients ( 2 females and 13 males), with a mean age of 35.5 years (range 25-50 years). All patients were complaining of post-traumatic defects. The time from the initial trauma to patient presentation to our department ranged from one week to one year. Soft tissue defects of the leg were from 15 to $25 \mathrm{~cm}$. All patients were evaluated preoperatively as regard to size and site of the defect, arterial injury patterns documented on preoperative duplex ultrasound, and donor site. All patients data and postoperative complications were included in Table 1.

\section{1) Anatomy}

The LD flap is based on thoracodorsal vessels that originate from the subscapular artery and runs along the border of the subscapular muscle and gives the angular and serratus branches which have many sizable side branches, including the circumflex scapular artery, angular branch, and serratus anterior branch. Subscapular artery and its branches are the basis for arterial anastomosis in LD flow-through flap.

\section{2) Surgical technique}

Preoperative designing and marking of the donor site were done in all cases (Fig. 1C, 2B). Two teams were started together, one team operated on the recipient site and the other on the donor site. Under general anesthesia, with the patient in the lateral position, debridement of all dead tissues was done (Fig. 1B). The recipient vessels, the posterior tibial (as in the first and second cases) or the anterior tibial arteries and its venae commitants (as in the third and fourth cases), were dissected in the distal portion of the leg. At the same time, the free myocutaneuos LD muscle flap was dissected from the contralateral side. The circumflex scapular vessels were dissected for $2 \mathrm{~cm}$ then clamped. The subscapular vessels were ligated at its junction with the axillary vessels (Fig. 1D, 3C). After the free muscle flap transferred to the prepared donor site,

Table 1. Patient's data

\begin{tabular}{|c|c|c|c|c|c|c|c|}
\hline $\begin{array}{l}\text { Case } \\
\text { No. }\end{array}$ & $\begin{array}{l}\text { Age } \\
(\mathrm{yr})\end{array}$ & Sex & Defect & $\begin{array}{l}\text { Flap size } \\
\quad(\mathrm{cm})\end{array}$ & Recipient vessels & Complications & $\begin{array}{l}2 \mathrm{yr} \\
\text { procedures }\end{array}$ \\
\hline 1 & 40 & Female & $\begin{array}{l}\text { Lower } 1 / 3 \text { of leg and } \\
\text { planter surface of foot }\end{array}$ & $20 \times 30$ & Posterior tibial vessels & - & - \\
\hline 2 & 36 & Male & $\begin{array}{l}\text { Lower } 1 / 3 \text { of leg and } \\
\text { planter surface of foot }\end{array}$ & $\begin{array}{l}\text { 1st flap: } 15 \times 20 \\
\text { 2nd flap: } 14 \times 18\end{array}$ & $\begin{array}{l}\text { 1st stage: anterior } \\
\text { tibial vessels } \\
\text { 2nd stage: posterior } \\
\text { tibial vessels }\end{array}$ & - & - \\
\hline 3 & 26 & Male & Lower $1 / 3$ of leg & $16 \times 20$ & Posterior tibial vessels & - & - \\
\hline 4 & 40 & Female & Dorsum of foot & $15 \times 10$ & Anterior tibial vessels & - & - \\
\hline 5 & 33 & Male & Medial aspect of foot & $15 \times 12$ & Posterior tibial vessels & - & - \\
\hline 6 & 25 & Male & Dorsum of foot & $14 \times 16$ & Anterior tibial vessels & - & - \\
\hline 7 & 42 & Male & Lower third of leg & $19 \times 22$ & Posterior tibial vessels & - & Debulking \\
\hline 8 & 38 & Male & Lower part of leg & $25 \times 15$ & Posterior tibial vessels & Heamatoma & Evacuation \\
\hline 9 & 40 & Male & Foot & $12 \times 18$ & Posterior tibial vessels & - & - \\
\hline 10 & 36 & Male & Foot & $20 \times 25$ & Posterior tibial vessels & $\begin{array}{c}\text { Partial } \\
\text { necrosis }\end{array}$ & Debridment \\
\hline 11 & 27 & Male & Foot & $14 \times 16$ & Posterior tibial vessels & $\begin{array}{l}\text { Partial } \\
\text { necrosis }\end{array}$ & Debridment \\
\hline 12 & 30 & Male & Foot & $12 \times 15$ & Posterior tibial vessels & - & - \\
\hline 13 & 32 & Male & Foot & $13 \times 15$ & Anterior tibial vessels & - & - \\
\hline 14 & 50 & Male & Foot & $13 \times 15$ & Posterior tibial vessels & $\begin{array}{c}\text { Partial } \\
\text { necrosis }\end{array}$ & Debridment \\
\hline 15 & 41 & Male & Foot & $14 \times 15$ & Posterior tibial vessels & - & - \\
\hline
\end{tabular}



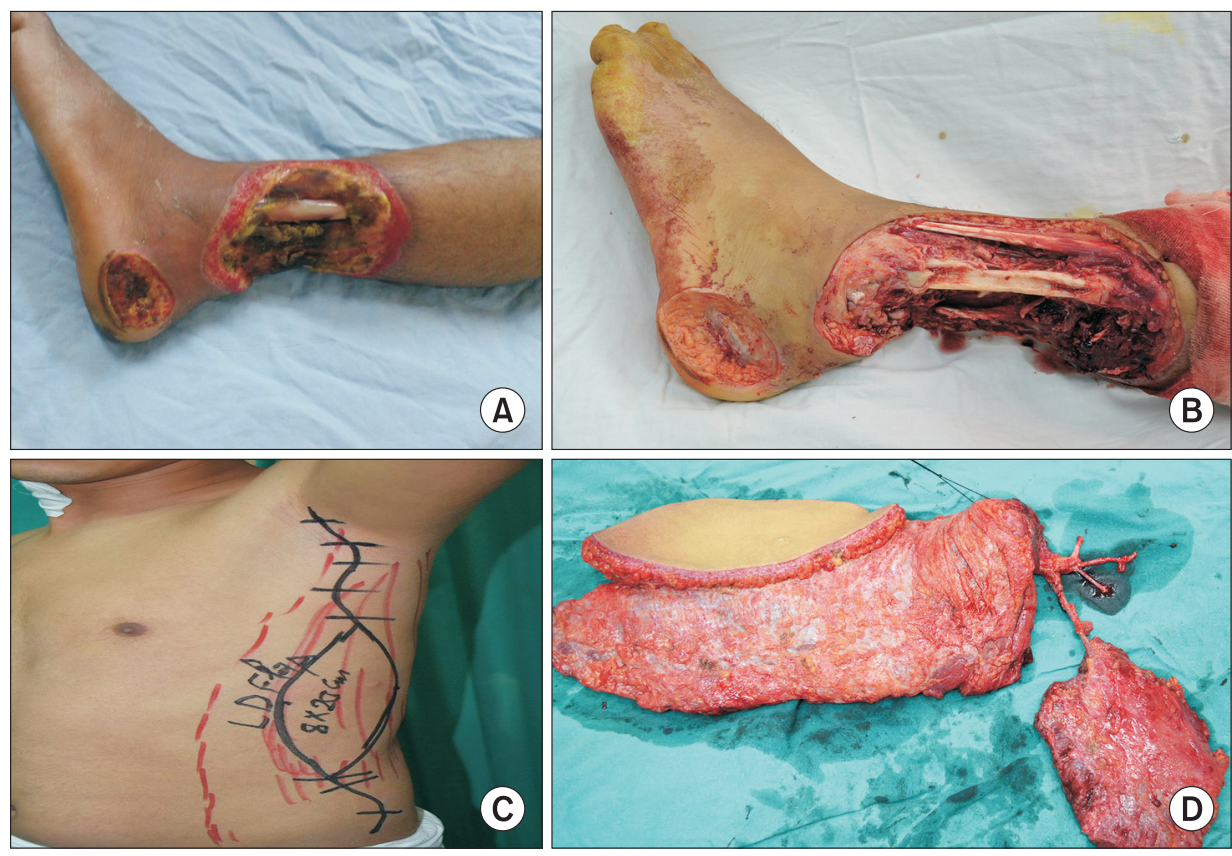

Fig. 1. A case of free tissue transfer for left leg. A patient who was reconstructed by chimeric flap flow-through technique for coverage of post-traumatic soft tissue loss of the lower third of the left leg. (A) Preoperative photograph. Demonstrates soft tissue loss of the lower third of the leg with the exposed fibula. (B) Debridement and excision of all devitalized tissues. (C) Design of the chimeric myocutaneuos flap. (D) Chimeric flap after separation.
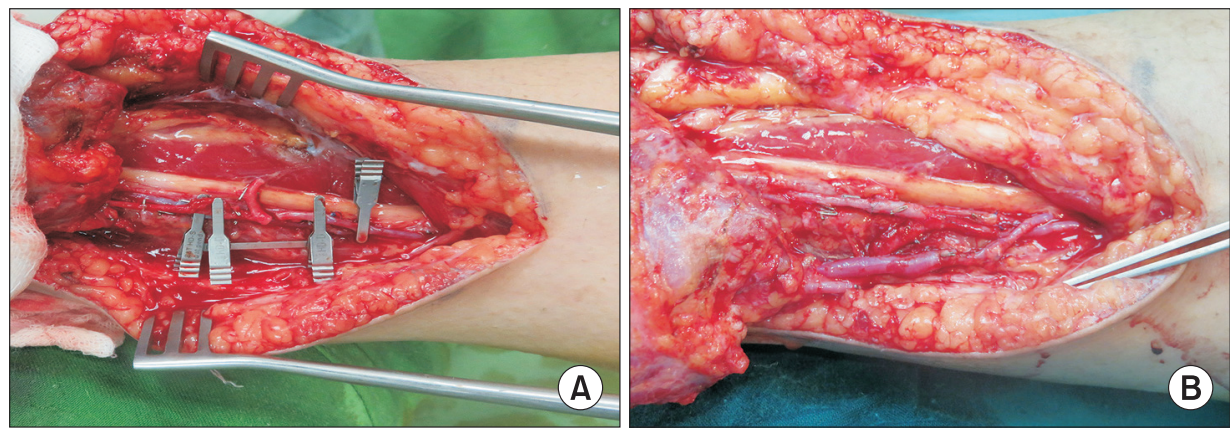

Fig. 2. A case of free tissue transfer for left leg. A patient who was
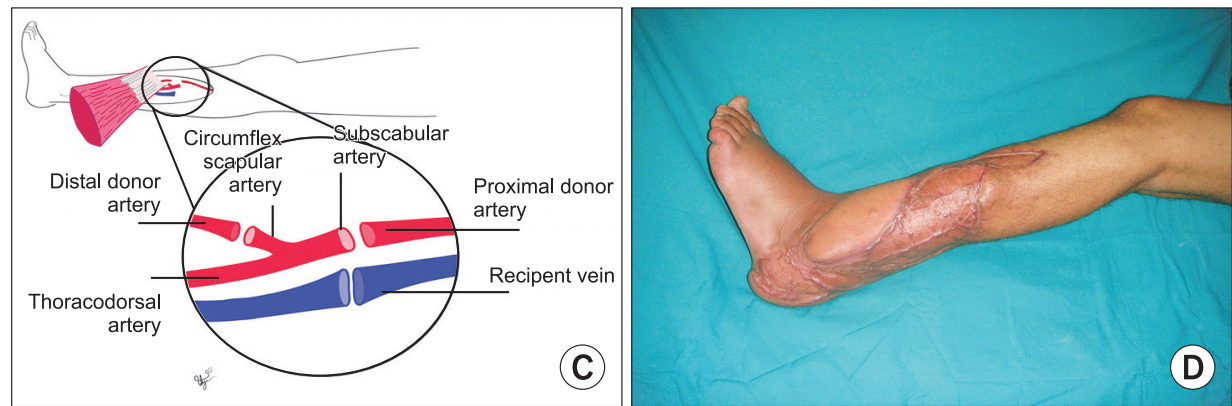
reconstructed by chimeric flap flowthrough technique for coverage of posttraumatic soft tissue loss of the lower third of the left leg. (A) Anterior tibial vessels preparation for anastomosis. (B) After anastomosis. (C) Diagram showing the vessels were anastomosed. (D) A photograph at follow-up on postoperative year 2 .

the posterior or anterior tibial artery was transected, and the subscapular artery with the circumflex scapular artery was interposed to anastomose between the transected artery (Fig. 2A). The proximal end of the subscapular vein was anastomoses end-to-end with the venae comitantes of the posterior (as in the first and second cases) or anterior tibial artery (as in the third and fourth cases) (Fig. $2 \mathrm{~B}, 2 \mathrm{C})$. A suction drain was inserted and the donor site at the lateral back was closed primarily. In some cases, a thick split skin graft was used to cover the muscle flap as shown in the first, second and fourth cases.

\section{Postoperative care}

The patients were transferred to the intensive care unit for 2 days. Monitoring the flap and the distal lower limb 

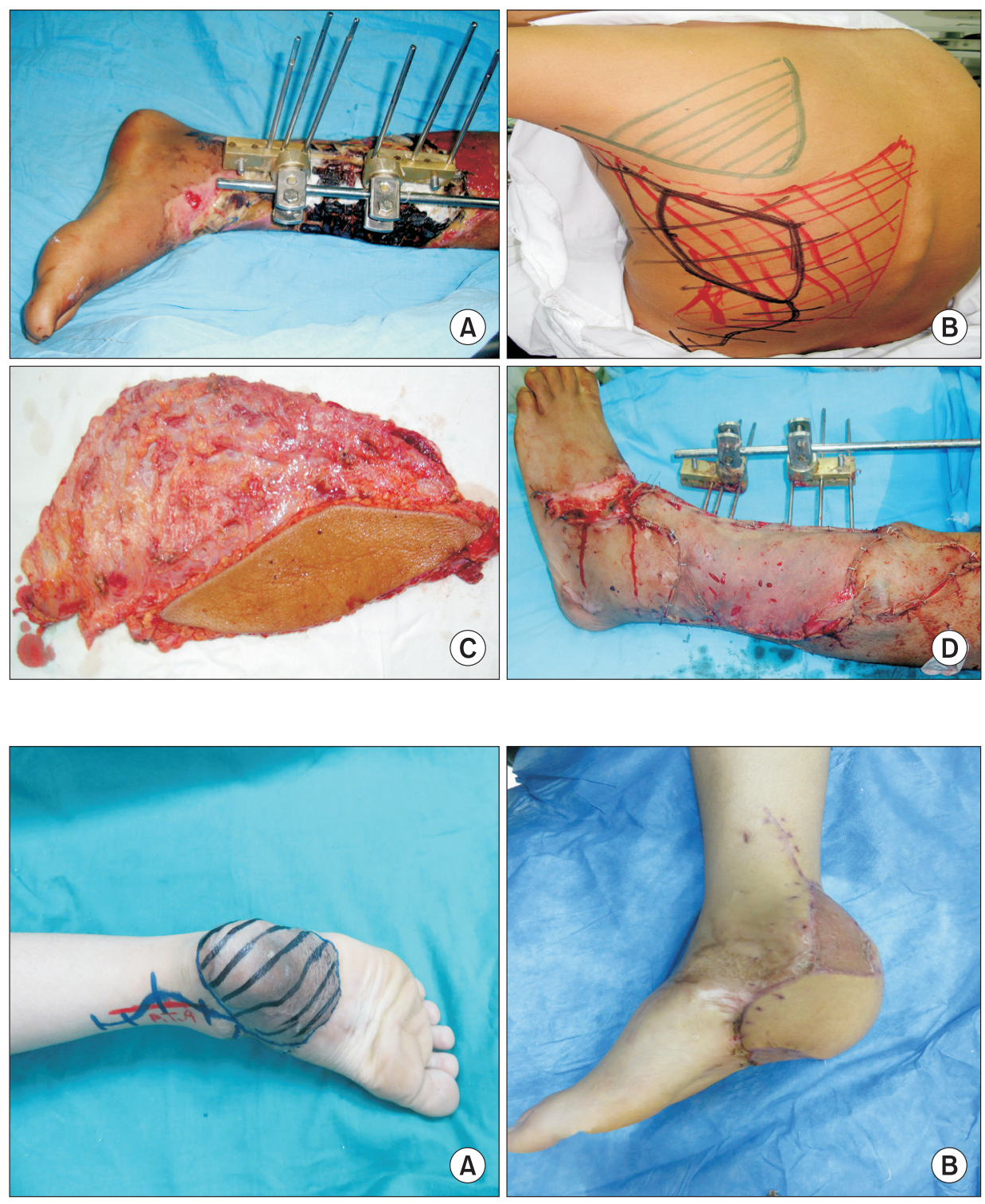

Fig. 3. A case of free latissimus myocutaneuos flap transfer. A male patient was reconstructed by free latissimus myocutaneuos flap transfer for salvage of the left leg. (A) Preoperative photograph. (B) Preoperative marking of the flap. (C) Latissimus myocutaneuos flap after separation. (D) An immediate postoperative photograph.

Fig. 4. A case of heel reconstruction. A patient with unstable, adherent scar overlying the right heel. The patient was reconstructed by free latissimus myocutaneuos flap transfer. (A) Preoperative photograph. (B) A photograph at follow-up on postoperative year 1 . perfusion was done. The patients were nursed in bed with the slightly elevated lower limb. Anticoagulants in the form of low molecular weight heparin were given to all patient's postoperative antibiotics were given. Drains were removed after 72 hours. The patients were discharged after 2 weeks and were followed as out patients. Interrupted skin sutures were removed after 10 days. All patients were followed-up for 6 months.

\section{Compliance with Ethical Standards}

The procedures performed in this study were in accordance with the ethical standards of the institutional research committee and with the 1964 Helsinki declaration and its later amendments or comparable ethical standards. This research was approved by Al Azhar University Research and Ethical Committee for the year 2017. Informed consent was obtained from all individual participants included in the study.

\section{RESULTS}

During the 2 years inclusion period, 15 patients were subjected to free latissimus muscle transfer by flowthrough technique for coverage of leg and/or foot defects. The patients required a mean of 15.3 sessions of opera- 
tion. All patients tolerated surgery well and all patients were followed postoperatively at regular intervals. The donor sites in all patients healed smoothly. All flaps were survived (Fig. 2D, 3D, 4B). Total survival incidence of these flaps was $100 \%$. The hematoma was developed under the flap in one patient and patient returned to the operative room for evacuation of the hematoma. In three patients, partial loss of the distal part of the flap that was treated conservatively. Patients 6 months postoperatively, debulking procedures were done in 2 cases. The patients started walking within 25 days.

\section{DISCUSSION}

Free flap transfer is an essential part of the limb-salvage surgery. The utility of the flow-through flap is now well established, and its indications for use continue to grow. The principal advantage of this flap is that it provides the opportunity for a single stage composite reconstruction of both soft tissue and vascular defects, making it particularly useful in the reconstruction of ischemic extremities. The clinical application of the flow-through LD flaps in other areas of the body, however, has been rarely reported $^{10}$.

The aim of this series is to evaluate the advantages and reliability of using flow-through flap for salvage of the lower limbs. End-to-end is impossible in cases with a single artery. Also, it represents as a closed circuit with a high incidence of flap congestion after limb dangling as mentioned by Miyamoto et al. ${ }^{11}$ flow-through free flap has the advantage of open-circuit circulation as the arterial inflow is diverted to the distal recipient artery. Miyamoto et al. ${ }^{2}$ compared the efficacy of flow-through anastomosis to both end-to-end and end-to-side arterial anastomoses in a rat model and they concluded that flowthrough arterial anastomosis delivers a higher patency rate than conventional end-to-end and end-to-side arterial anastomoses when there is little size discrepancy. On the other hand, regarding the venous anastomosis, Fujiki et al. ${ }^{12}$ suggested the superiority of flow-through venous anastomosis over conventional techniques. In our series, the venous anastomosis was done by the end-to-end technique with no venous congestion or thrombosis in all cases. So, we can avoid two anastomotic sites for venous flow-through and also the procedure time became shorter.

LD muscle flaps are commonly used for the reconstruction of distal limbs, with their reliability and versatility having been established ${ }^{13}$. LD flap offers sufficient soft tissue to cover lower limb defects. Its main vascular pedicle is long and can provide the opportunity for a flowthrough flap.

In this study, we use flow-through LD muscle flaps for coverage of large leg defects with inadequate circulation in the distal extremity. LD muscle is rich in blood supply, has long pedicle, large surface area, and no major donor site morbidity. The distal run off vessels was the circumflex scapular artery as it matched well with the recipient artery and located near the proximal end of the pedicle so the intervening segment between the proximal and distal segments of the recipient's vessel was short. Two teams were working together to minimize the operative time that represents an important advantage of its using.

By using flow-through chimeric free flaps, simultaneous coverage of large defect and revascularization of the distal limb can be obtained. In our series, LD and serratus anterior muscles flap were used for coverage of large leg defect in a case that was impossible to coverd except by two free flaps. This represents a major advantage for flow-through flaps.

The distal limb circulation was not affected in all cases by the steal phenomenon that assumed decreasing blood flow in the recipient artery after using the flow-through technique. Nasir et al. ${ }^{14}$ demonstrated that flow-through flaps in vascularized injured extremity did not disturb distal leg circulation in spite of increased blood flow in the recipient and pedicle arteries by using Doppler ultrasonography. The limitation of this technique only in case of a vascular defect in again pedicle as the flow-through of the LD can't replace a long defect in the door artery.

\section{CONCLUSION}

The use of the flow-through technique is a very useful tool for sure vascularization of the flap and revasculariza- 
tion of the distal limb at the same time. An LD muscle flap is the workhorse flap for reconstruction of the distal extremity by flow-through the free flap.

\section{CONFLICTS OF INTEREST}

The authors have nothing to disclose.

\section{REFERENCES}

1. Dotson RJ, Bishop AT, Wood MB, Schroeder A. End-toend versus end-to-side arterial anastomosis patency in microvascular surgery. Microsurgery. 1998;18:125-8.

2. Miyamoto S, Okazaki M, Ohura N, Shiraishi T, Takushima A, Harii K. Comparative study of different combinations of microvascular anastomoses in a rat model: endto-end, end-to-side, and flow-through anastomosis. Plast Reconstr Surg. 2008;122:449-55.

3. Koshima I, Fujitsu M, Ushio S, Sugiyama N, Yamashita S. Flow-through anterior thigh flaps with a short pedicle for reconstruction of lower leg and foot defects. Plast Reconstr Surg. 2005;115:155-62.

4. Kim JT, Kim CY, Kim YH. T-anastomosis in microsurgical free flap reconstruction: an overview of clinical applications. J Plast Reconstr Aesthet Surg. 2008;61:1157-63.

5. Soutar DS, Scheker LR, Tanner NS, McGregor IA. The radial forearm flap: a versatile method for intra-oral reconstruction. Br J Plast Surg. 1983;36:1-8.

6. Sakurai H, Yamaki T, Takeuchi M, Soejima K, Kono T, Nozaki M. Hemodynamic alterations in the transferred tis- sue to lower extremities. Microsurgery. 2009;29:101-6.

7. Muramatsu K, Shigetomi M, Ihara K, Kawai S, Doi K. Vascular complication in free tissue transfer to the leg. Microsurgery. 2001;21:362-5.

8. Lorenzo AR, Lin CH, Lin $\mathrm{CH}$, et al. Selection of the recipient vein in microvascular flap reconstruction of the lower extremity: analysis of 362 free-tissue transfers. J Plast Reconstr Aesthet Surg. 2011;64:649-55.

9. Godina M. Preferential use of end-to-side arterial anastomoses in free flap transfers. Plast Reconstr Surg. 1979;64:673-82.

10. Bullocks J, Naik B, Lee E, Hollier L Jr. Flow-through flaps: a review of current knowledge and a novel classification system. Microsurgery. 2006;26:439-49.

11. Miyamoto S, Kayano S, Fujiki M, Chuman H, Kawai A, Sakuraba M. Early mobilization after free-flap transfer to the lower extremities: preferential use of flowthrough anastomosis. Plast Reconstr Surg Glob Open. 2014;2:e127.

12. Fujiki M, Miyamoto S, Sakuraba M. Flow-through anastomosis for both the artery and vein in leg free flap transfer. Microsurgery. 2015;35:536-40.

13. Koshima I, Saisho H, Kawada S, Hamanaka T, Umeda N, Moriguchi T. Flow-through thin latissimus dorsi perforator flap for repair of soft-tissue defects in the legs. Plast Reconstr Surg. 1999;103:1483-90.

14. Nasir S, Aydin MA, Sonmez E, Baykal B. Flow-through free latissimus dorsi flap for reconstruction of injured limbs: evaluation of hemodynamic effects on extremity circulation. Ann Plast Surg. 2010;65:164-9. 